\title{
The Numerical Analysis of Landslide Anti-slide Pile Mechanism under the Condition of Rainfall
}

\author{
Chen Zhao ${ }^{1, ~ a, ~ Y o n g ~ F e n g ~}{ }^{2, b}$, Xuguang $\mathrm{Li}^{2, \mathrm{c}}$ \\ ${ }^{1}$ Henan Vocational College of Water Conservancy and Environment, Zheng Zhou,China 450001 \\ ${ }^{2}$ College of Civil Engineering and Architecture, Henan University of Technology, Zheng Zhou \\ ,China, 450001

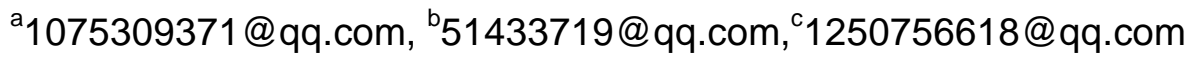

Keywords: ABAQUS ; fluid solid coupling ; soil arch effect

\begin{abstract}
For now, the engineering landslide caused by rainfall is increasing, but the current research mainly stays in two-dimensional space which neither tallies with the actual three-dimensional space, nor lacks the related research on the influence of the landslide-function anti-slide pile system under different rainfall conditions. Therefore, it is necessary to make a further discussion. With the example of Chayang station landslide, this paper has made a three-dimensional calculation model of the interaction between landslide and anti-slide pile by using ABAQUS numerical analysis. Based on the unsaturated soil theory, the ABAQUS numerical analysis adopts the fluid solid coupling method to simulate the distribution law of the landslide-function anti-slide pile under different rainfall conditions. The research shows that the unsaturated soil changes from negative pressure zone to positive pressure zone and the corresponding soil arch effect weakens. And with the increase of the slide mass depth, the influence sphere of soil arch effect is reduced gradually. In this paper, related research conclusions can provide beneficial references for theoretical analysis of the interaction between anti-slide pile and soil mass, anti-slide pile design and construction.
\end{abstract}

\section{Introduction}

With the advantage of anti-sliding ability and wide application conditions, anti-slide piles have already been used in most landslide control engineering. In recent years, with the wide application of anti-slide pile in the engineering, some important results have been achieved on the practice and theoretical research of anti-slide pile, landslide anti-slide pile mechanism analysis and optimization design both in China and abroad.

The current research status of the landslide-function anti-slide pile system shows that the current research mainly stays in two-dimensional space which is not in conformity with the actual three-dimensional space. Therefore, it is necessary to make a further discussion.

Landslide instability is mostly related to the rainfall. Rainfall can reduce the shear strength of rock and soil mass, raise underground water level and the pore water pressure. Moreover, the result of long-time high intensity rainfall is that the above area of underground water level stabilization appears transient saturated zone. And pore water pressure in the corresponding area will get higher, which will reduce the shear strength of soil mass itself to cause landslides and other geological disasters. However, there is still lacking in the related research on the influence of the landslide-function anti-slide pile system under different rainfall infiltration conditions.

\section{Engineering outline}

Engineering outline.Chayang station of Zhanglong railway is located in railway running mileage pile number Zhanglong railway K160+350 K161+100, with the length of this railway $0.76 \mathrm{~km}$. But now, within the scope of research, there is a new landslide due to the human engineering excavation and natural rainfalls. The direct results of this landslide are the drumlin and sag of the farmland, 
displacement and settlement of railway track. According to the above series of sliding trace of rock and soil mass, the rock and soil mass is judged comprehensively as unstable that may slides once again.

Stratum condition. According to the investigation data, the stratum situation in field area from the surface of the ground is shown in Table 1 from top to bottom, in turn.

\begin{tabular}{|c|c|c|c|c|c|c|}
\hline $\begin{array}{l}\text { Soil } \\
\text { layer } \\
\text { name }\end{array}$ & $\begin{array}{l}\text { Thickne } \\
\text { ss /m }\end{array}$ & $\begin{array}{l}\text { Severe / } \\
\mathrm{kN} \bullet \mathrm{m}-3\end{array}$ & $\begin{array}{l}\text { cohesiv } \\
\mathrm{e} \\
\text { strength } \\
/ \\
\quad \mathrm{kPa}\end{array}$ & $\begin{array}{l}\text { Internal } \\
\text { friction } \\
\text { angle / }\end{array}$ & $\begin{array}{c}\text { modulus } \\
\text { of } \\
\text { deforma } \\
\text { tion } \\
\text { /Mpa }\end{array}$ & $\begin{array}{c}\text { Poiss } \\
\text { on } \\
\text { rati } \\
\text { o }\end{array}$ \\
\hline $\begin{array}{l}\text { Miscella } \\
\text { neous fill } \\
\text { soil }\end{array}$ & $2.1 \sim 5.5$ & 17.5 & 17.8 & 16 & 9 & 0.4 \\
\hline silty clay & $5.3 \sim 8.9$ & 18.9 & 21.4 & 21 & 18 & 0.33 \\
\hline $\begin{array}{c}\text { Full } \\
\text { weathere } \\
\mathrm{d} \\
\text { sandston } \\
\mathrm{e}\end{array}$ & $3.2 \sim 10.9$ & 19.3 & 22.8 & 23 & 18.6 & 0.34 \\
\hline $\begin{array}{l}\text { Weather } \\
\text { ed } \\
\text { epidotite }\end{array}$ & $2.8-15.6$ & 20.6 & 23.4 & 24.5 & 19 & 0.32 \\
\hline
\end{tabular}

Project design of landslide mass and anti-slide pile

To ensure the safety of the station and adjacent buildings, based on the preliminary control program, the anti-side piles with $2 \times 3$ rectangular sections are set up at a distance of $7.5 \mathrm{~m}$ from the railway red line (that is, $32.5 \mathrm{~m}$ from the railway central lines). As for the pile length, the minimum is $35 \mathrm{~m}$ and the maximum is $42 \mathrm{~m}$.

\section{The three-dimensional analysis of landslide mass function and anti-slide pile system}

ABAQUS is a set of powerful finite element software, which can deal with relatively simple linear analysis to engineering complex nonlinear problems.

Selection of the soil constitutive model .This simulation is about (unsaturated soil) the rock and soil mass, with the constitutive model of Mohr-Coulomb (Mohr-Coulomb)

The relationship between the material permeability coefficient and the matrix suction is:

$$
k_{w}=a_{w} k_{w s} /\left[a_{w}+\left(b_{w}\left(u_{a}-u_{w}\right)\right) c_{v}\right]
$$

In the formula, $\mathrm{Ua}$ is the atmospheric pressure, as a result of the contact with slope, so it is taken to 0 . Kw is the permeability coefficient of soil saturation, taking $5.0 \times 10-6 \mathrm{~m} / \mathrm{s}$; aw, bw, cw are the material coefficient, taking 1000, 0.01, 1.7 .

The relationship between saturation and matrix suction is:

$$
s_{r}=s_{i}+\left(s_{n}-s_{i}\right) a_{s} /\left[a_{s}+\left(b_{s} \times\left(u_{a}-u_{w}\right)\right)^{c_{s}}\right]
$$

In this formula, the $\mathrm{Sr}$ is saturation; as the residual saturation, the value of $\mathrm{Si}$ is 0.08 ; $\mathrm{Sn}$ is the maximum saturation, taking 1; the As, Bs, Cs are the material coefficient, taking 1, 0.00005, 3.5.

Establishment of the numerical analysis model of ABAQUS. According to the geological analysis, slope geological model can be generalized into: miscellaneous fill soil, silty clay, full weathered sandstone, and weathered epidotite. The scope of three-dimensional geological model should respectively be $767 \mathrm{~m}$ (X direction), parallel to the axis direction of the landslide mass, $450 \mathrm{~m}(\mathrm{Y}$ direction), perpendicular to the axis direction of the landslide mass, and $105 \sim 273 \mathrm{~m}$ (the $\mathrm{Z}$ axis, elevation of $0 \sim 167 \mathrm{~m}$ ), perpendicular of the tallest height. The front side and back side (landslide direction) restrain the displacement of $\mathrm{X}$ and $\mathrm{Y}$ direction. Two sides restrain the displacement of $\mathrm{Y}$ direction and the bottom restrains the displacement of three directions. The ground surface is free surface. Given the gravity and surface load, the function of water level can be simulated by using seepage models in the program. 


\section{The three-dimensional analysis results of the function system}

The result analysis of pore pressure in rainfall. The pore water pressure of landslide is shown in Fig.1. The diagram of the pore pressure distribution after rainfall infiltration is obviously different from the initial pore pressure distribution. Before rainfall, the pore pressure presents linear distribution along the stratum. But later, at the top of the rock and soil mass, central part and slope under a certain range, the pore water pressure increased significantly. The suction area decreases and the matrix suction decreases, too. Meanwhile, in the process of rainfall, the a, b, c figure show that the internal area of rock and soil mass all failed to meet the saturation which are still in negative pressure zone. But central part and slope under a certain range in d figure, the pore pressure has been positive, which shows that the landslide mass has appeared saturated zone.

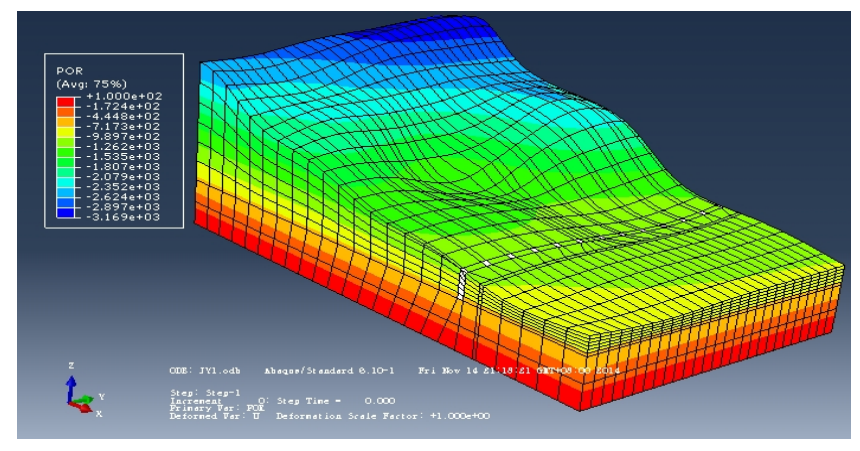

a. Pore pressure distribution in one

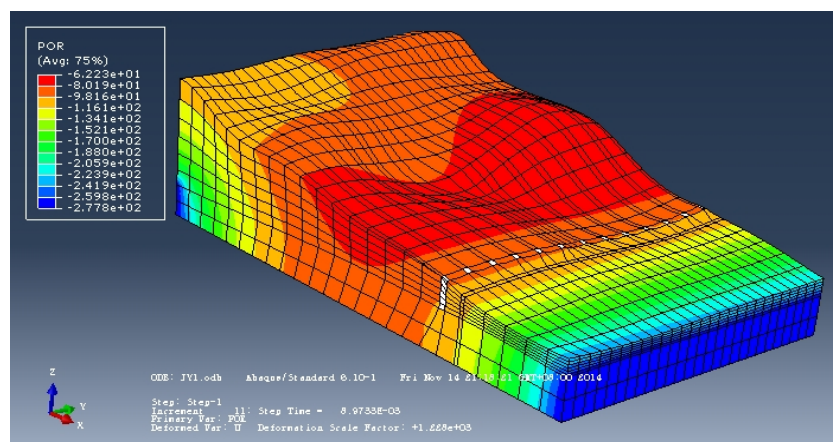

c. Pore pressure distribution in three

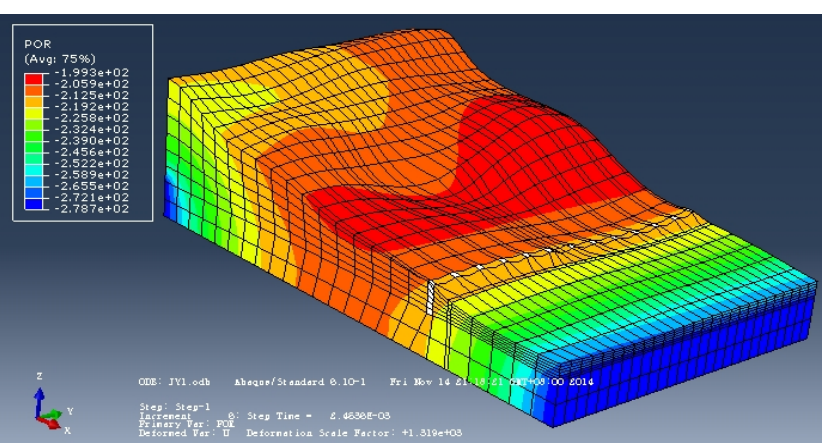

b. Pore pressure distribution in two

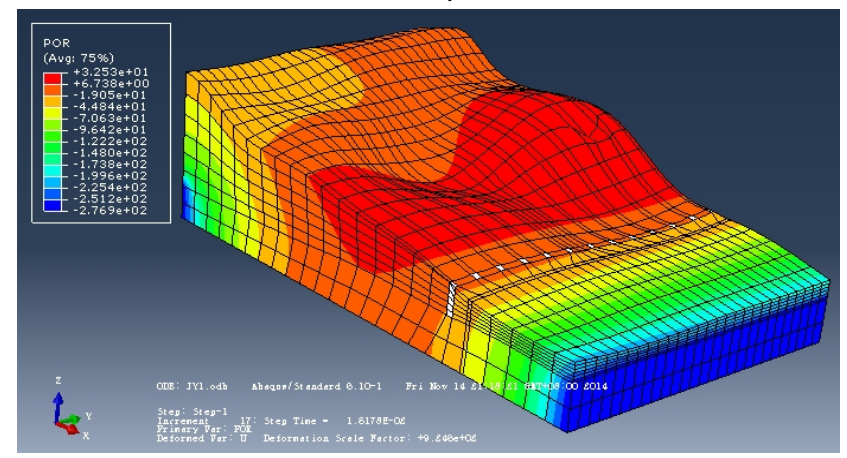

d. Pore pressure distribution in four

Fig. 1 Every mode of pore pressure distribution map

The displacement analysis of rock and soil mass in rainfall.The horizontal displacement of landslide is shown in Fig. 1, and under model 2, the horizontal displacement of the slope top and bottom is larger. With the increase of rainfall, the maximum horizontal displacement of slope gradually transit from the top and bottom of the slope to the mid-slope. After the rainfall infiltration, the pore pressure of rock and soil mass increases and the effective stress decreases. This will lead to larger mid-slope horizontal displacement due to the influence of gravity. At the same time, it can be seen that there is the certain expansion in mid-slope which is mainly caused by the rainfall. The rainfall leads to the increase of landslide mass saturation but the decrease of suction and effective stress, thus the unloading rebound phenomenon of slope appears. This is why the Fig. appears the landslide phenomenon.

The impact of soil arch effect in rainfall. With the increase of rainfall, the soil arch effect weakens gradually. Reasons are as follows: with the rainfall infiltration, the soil mass pore pressure increases, so does the saturation. And the shear strength of rock and soil mass weakens soil arch effect, as a result of the decrease of effective stress. 
The soil arch effect analysis in three-dimensional space.Because of the soil arch effect, the maximum principal strain of the slip mass has changed significantly by the anti-slide pile. The influence sphere of pile stress gradually decreases from top to bottom, which shows that with the increase of slip mass depth, the influence sphere of soil arch effect

gradually decreases. Therefore, in anti-slide pile practice, people should consider the law that soil arch effect is reduced with the depth of slip mass, and work on anti-slide pile designs which is based on the influence sphere of the soil arch effect.

\section{Conclusion}

(1) After rainfall infiltration, the pore pressure distribution is obviously different from the initial pore pressure distribution. Before rainfall, the pore pressure presents linear distribution along the stratum. But later, within the slope under a certain range, significant changes have occurred on pore water pressure, including the decreased suction area and the reduced matrix suction. At the same time, in the process of rainfall, the landslide geological hazards could occur at any time when the rainfall reaches a certain point.

(2) With the increase of rainfall, the horizontal displacement of landslide mass becomes larger due to the influence of gravity. Meanwhile, some certain expansion phenomenon will appear in the actual rock and soil mass, which is mainly caused by the rainfall. The rainfall leads to the increase of side-slope saturation but the decrease of geological suction and effective stress, thus the unloading rebound phenomenon of slope appears.

(3) Through the analysis on the impact of soil arch effect in rainfall, conclusions are made: with rainfall infiltration, the pore pressure increases, so does the saturation. And the shear strength of rock and soil mass weakens soil arch effect, as a result of the decrease of effective stress.

(4) The influence sphere of pile stress gradually decreases from top to bottom, which shows that with the increase of slip mass depth, the influence sphere of soil arch effect gradually decreases.

\section{Acknowledgements}

This work was financially supported by 2014 HeNan province water conservancy science and technology research projects (GG201436), 2015 HeNan province science and technology research project (152102310407)

\section{Reference:}

[1] Qing Lv, Hongyue Sun, Yuequan Shang, Anti-slide piles been arch effect mechanism and growth rule. 2010:0559-950(2010)04-0471-06.

[2] Depei Zhou, Shiguo Xiao, Xiong Xia,Reasonable anti-slide pile spacing in the slope engineering, journal of geotechnical engineering,2004.26(1)

[3] Liangxiao Xong, Tianbin Li, The soil arch effect in the application of anti-slide pile engineering [J]. Journal of disaster prevention and mitigation engineering, 2005, 25 (3) : 275-277.

[4] Fusong Fan.Numerical study on landslide anti slide pile soil arching effect. China University of Geosciences (Wuhan) Master's degree thesis.2012

[5] Kang Fei, Jianwei Zhang, ABABQUS application in geotechnical engineering [M]. 2010 ; 205-233

[6] The China meteorological administration, The weather forecast distribution and transmission management approach. 